\title{
Development of Robust Electrocatalysts Comprising Single-atom Sites with Designed Coordination Environments
}

\author{
Kazuhide KAMIYA ${ }^{a, b, c, *}$
}

a Research Center for Solar Energy Chemistry, Osaka University, 1-3 Machikaneyama, Toyonaka, Osaka 560-8531, Japan

b Graduate School of Engineering Science, Osaka University, 1-3 Machikaneyama, Toyonaka, Osaka 560-8531, Japan

c Japan Science and Technology Agency (JST) PRESTO, 4-1-8 Honcho, Kawaguchi, Saitama 332-0012, Japan

*Corresponding author: kamiya@chem.es.osaka-u.ac.jp

\section{ABSTRACT}

Single-atom catalysts (SACS), which are composed of singly isolated metal sites and heterogeneous supports, have recently attracted intensive attention as a novel category of electrocatalysts. SACs can not only ultimately reduce the loading amount of noble metals but also exhibit unique reaction activity and selectivity for many reactions. However, the design flexibility of conventional supports of SACs, including nanocarbons and metal oxides, is poor. Therefore, designing coordination environments of metal centers in SACs, which are one of the most significant parameters governing their electrocatalytic properties, has been challenging. This review outlines the synthesis of two kinds of SACs with defined coordination structures and their unique electrocatalytic activities. First, graphenes doped with metals $(\mathrm{Fe}, \mathrm{Cu}$, and $\mathrm{Ni})$ and nitrogen atoms, which were prepared by a short-duration heat treatment,

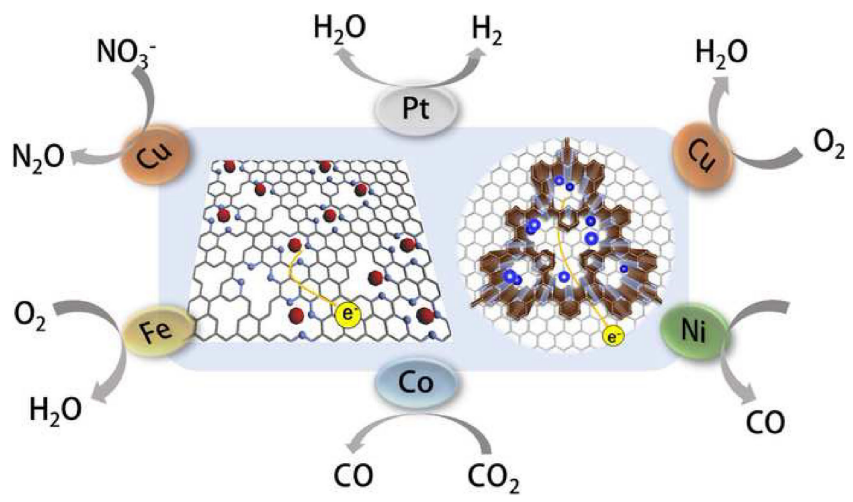
function as efficient electrocatalysts for oxygen reduction reactions and $\mathrm{CO}_{2}$ reduction reactions. Second, metal-doped covalent organic frameworks, which are a class of porous conjugated polymers, exhibit unique electrocatalytic selectivity compared with bulk metals.

(C) The Author(s) 2020. Published by ECSJ. This is an open access article distributed under the terms of the Creative Commons Attribution 4.0 License (CC BY, http://creativecommons.org/licenses/by/4.0/), which permits unrestricted reuse of the work in any medium provided the original work is properly cited. [DOI: 10.5796/electrochemistry.20-00089]. Uploading "PDF file created by publishers" to institutional repositories or public websites is not permitted by the copyright license agreement.

Keywords : Single-atom Electrocatalyst, Covalent Organic Frameworks, Metal-nitrogen-doped Graphenes

\section{Introduction}

Electrochemical devices for applications related to solving energy and environmental issues, such as electrochemical energy storage, ${ }^{1,2}$ artificial photosynthesis, ${ }^{3,4}$ and pollutant degradation, ${ }^{5,6}$ are becoming increasingly vital because they can operate under mild conditions without toxic reactants. Electrocatalysts are one of the most important components governing the activity and selectivity of such electrochemical devices. Existing electrocatalysts are classified

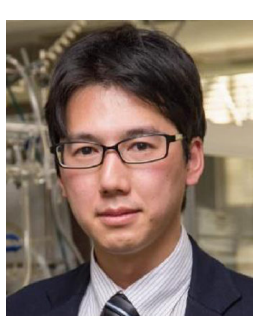

Kazuhide Kamiya (Associate Professor, Osaka University)

Kazuhide Kamiya received his Ph.D. degree from the University of Tokyo under the supervision of Prof. Kazuhito Hashimoto and became an assistant professor of his group in 2013. He then joined Research Center for Solar Energy Chemistry of Osaka University (Nakanishi group) as the assistant professor in April 2016. He was promoted to associate professor at the same center in 2018. He had been a researcher of the PRESTO project of JST from 2014 to 2018. His current research interests include the design of efficient photo- and electrocatalysts, which consist of porous conjugated polymers and carbon-based materials. into two broad categories: molecular-based catalysts (e.g., organometallics and organic molecules) and inorganic bulk materials (e.g., metal and metal oxide nanoparticles and nanocarbons). The most important advantage of molecular-based catalysts is their high design flexibility, which enables the efficient modulation of the geometrical and electronic structures of metal centers. However, the fragility of these materials remains a substantial problem. By contrast, although inorganic bulk materials exhibit high durability, their design flexibility is relatively poor. Thus, imparting electrocatalysts with both design flexibility and robustness is an essential and challenging task.

Single-atom catalysts (SACs) might simultaneously satisfy the two aforementioned requirements. SACs are composed of singly isolated metal sites and heterogeneous and robust conductive supports. $^{7-12}$ Thus, SACs should be as relatively stable as inorganic catalysts. In addition, when highly designable materials are used as supports for SACs, the coordination environments of the metal centers become highly flexible, similar to homogeneous organometallic catalysts, which likely leads to unique catalytic activity and selectivity. However, the coordination structure of single-metal sites on conventional supports, such as nanocarbons and metal oxides, is limited because of the low design flexibility of the supports. Given this background information, we have developed two novel approaches to attaining designable coordination structures of 


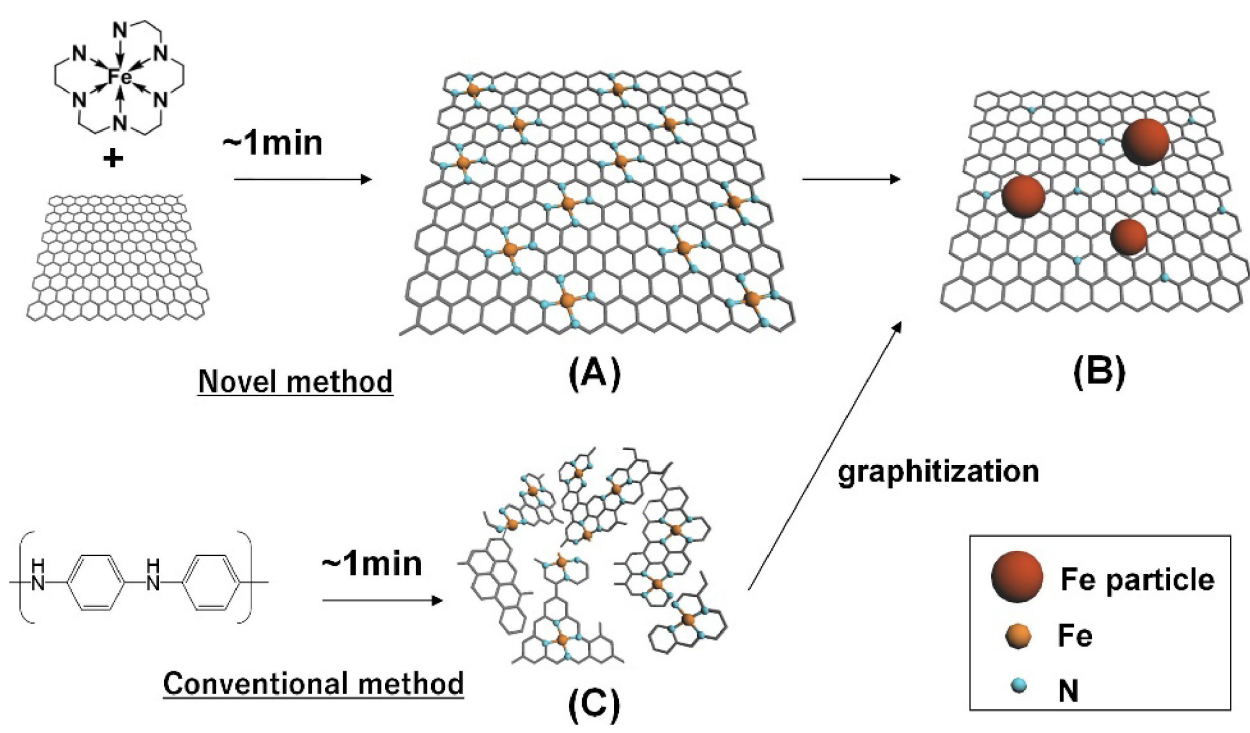

Figure 1. Schematic of the metal center with heat-treatment duration used to synthesize $M-\mathrm{N}-\mathrm{Grs}$. Reproduced with permission from Ref. 22. Copyright 2014 Wiley-VCH Verlag GmbH \& Co. KGaA.

single-atom sites in electrocatalysts: (i) a short-duration heat treatment of graphene oxides in the presence of metal complexes and (ii) the use of covalent organic frameworks (COFs) as supports. The present paper details our recent studies on SAC electrocatalysts with unique catalytic properties.

\section{Metal-nitrogen-doped Graphenes}

\subsection{Oxygen reduction reactions catalyzed by $\mathrm{Fe}-\mathrm{N}-$ or $\mathrm{Cu}-\mathrm{N}-$ doped graphenes}

Functioning as the cathode reaction in various types of fuel cells, the oxygen reduction reaction (ORR) is a critical process. Pt is used as a practical ORR electrocatalyst; however, because Pt is rare and therefore expensive, interest in a non-noble-metal replacement for Pt is increasing. One promising class of candidates for such catalysts is carbon-based materials synthesized by the pyrolysis of organic substances containing nitrogen. ${ }^{13-20}$ In this method, metals such as $\mathrm{Co}$ and $\mathrm{Fe}$ are needed during the pyrolysis. The aggregated metal nanoparticles catalyze graphitization. The resultant carbon materials containing metals and nitrogen exhibit ORR activity. The overpotential for these catalysts is $100-300 \mathrm{mV}$ greater than that for the standard $\mathrm{Pt} / \mathrm{C}$ catalysts. In general, the graphitization process requires a high-temperature heat treatment longer than $1 \mathrm{~h}$. However, this long-period heat treatment leads to the desorption of the dopants and to the formation of metal aggregates such as metal nanoparticles or metal carbides; both of which decrease the ORR electrocatalytic activity.

In the present study, we developed a method for the instantaneous synthesis of graphene doped with $\mathrm{N}$ and $\mathrm{Fe}(\mathrm{Fe}-\mathrm{N}-\mathrm{Gr})$ by using graphene oxides (GOs) as a precursor. ${ }^{21,22}$ Although the existing pyrolysis method requires an extended heat treatment to form $s p^{2}$ carbon structures, as previously mentioned, the use of GOs as the precursor enables the heat-treatment time to be drastically shortened. In the proposed method, GOs prepared by the modified Hummers method are quickly placed under an $\mathrm{Ar}$ atmosphere at $900{ }^{\circ} \mathrm{C}$, along with $\mathrm{N}$ and $\mathrm{Fe}$ sources; the sample is then maintained at $900^{\circ} \mathrm{C}$ under Ar for just $45 \mathrm{~s}$ (Fig. 1).

The ORR activity of the resultant $\mathrm{Fe}-\mathrm{N}-\mathrm{Gr}$ in $0.5 \mathrm{M} \mathrm{H}_{2} \mathrm{SO}_{4}$ solution is shown in Fig. 2a. The onset potential of our Fe-N-Gr catalyst for the ORR was approximately $0.85 \mathrm{~V}$ vs. a reversible hydrogen electrode (RHE) ${ }^{21,22}$ Notably, the ORR activity is much lower for $\mathrm{Fe}$ - and $\mathrm{N}$-graphenes than for $\mathrm{Fe}-\mathrm{N}-\mathrm{Gr}$. Thus, codoping of
$\mathrm{Fe}$ and $\mathrm{N}$ is necessary to achieve enhanced catalytic activity. We have confirmed that, when the heat-treatment period is extended, the $\mathrm{Fe}-\mathrm{N}$ coordination bond is broken and the electron numbers for the ORR decrease (Fig. 2b).

The aforementioned method was also applied to the synthesis of $\mathrm{Cu}-\mathrm{N}-\mathrm{Gr}$ as an ORR catalyst using 3,5-diamino-1,2,4-triazole $(\mathrm{Cu}-$ DAT) as the precursor. ${ }^{23}$ The resultant Cu-based catalysts exhibited high activity toward the ORR, with an onset potential of $790 \mathrm{mV}$ in a neutral solution (Fig. 2c). Importantly, the catalyst exhibited greater stability than $\mathrm{Cu}$-DAT without heat treatment because of the anchoring of active $\mathrm{Cu}$-sites into the graphene substrate via the $\mathrm{Cu}-\mathrm{N}$ coordination bonds (Figs. $2 \mathrm{c}$ and $2 \mathrm{~d}$ ).

\section{2 $\mathrm{CO}_{2}$ reduction to $\mathrm{CO}$ by $\mathrm{Ni}-\mathrm{N}$-doped graphene}

Numerous studies on developing organometallic-based carbon dioxide $\left(\mathrm{CO}_{2}\right)$ reduction electrocatalysts have been reported. Nickel1,4,8,11-tetraazacyclotetradecane (Ni-cyclam) and its derivatives have been reported to efficiently reduce $\mathrm{CO}_{2}$ to carbon monoxide (CO) with almost no hydrogen evolution, which is a reaction that competes with the $\mathrm{CO}_{2}$ reduction reaction (CRR). ${ }^{24,25}$ Given that carbon-based catalysts containing nitrogen and metal atoms catalysts are more stable than the corresponding organometallics, we expected the Ni-N coordination sites in an $s p^{2}$ carbon matrix to exhibit both efficient $\mathrm{CO}_{2}$ reduction activity and high robustness. Although Varela et al. have reported that single $\mathrm{Fe}-\mathrm{N}-$ or $\mathrm{Mn}-\mathrm{N}-$ doped carbon-based materials catalyze the reduction of $\mathrm{CO}_{2}$ to $\mathrm{CO},{ }^{26,27}$ our work was the first report of $\mathrm{Ni}-\mathrm{N}$-doped carbon materials. This scarcity of information related to $\mathrm{Ni}-\mathrm{N}$-doped carbon materials is likely attributable to $\mathrm{Ni}-\mathrm{N}$ bonds being more fragile under high-temperature heat treatment conditions than $\mathrm{Fe}-\mathrm{N}$ and $\mathrm{Co}-\mathrm{N}$ bonds. ${ }^{28,29}$ We therefore used the short heat treatment to synthesize Ni/N-Gr as a CRR electrocatalyst (Fig. 3a). ${ }^{30}$

Figures $3 \mathrm{~b}$ through $3 \mathrm{~g}$ show current density $(j)$ vs. potential $(U)$ curves and faradaic efficiencies (FEs) of $\mathrm{CO}$ production for $\mathrm{Ni} / \mathrm{N}-$ $\mathrm{Gr}$, a Ni metal electrode, and $\mathrm{N}-\mathrm{Gr}$. The increases in the onset potential and cathodic current by the addition of $\mathrm{CO}_{2}$ were observed for $\mathrm{Ni} / \mathrm{N}-\mathrm{Gr}$, whereas the current clearly decreased in the presence of $\mathrm{CO}_{2}$ for a Ni-metal electrode and $\mathrm{N}-\mathrm{Gr}$. In addition, with Ni/N$\mathrm{Gr}$, the FE of CO is greater than $90 \%$ in the potential range from -0.7 to $-0.9 \mathrm{~V}$ vs. RHE. We note here that the only other main product is $\mathrm{H}_{2}$ over the entire examined potential region. ${ }^{30}$ At more negative potentials, the hydrogen evolution reaction (HER) gradual- 
(a)

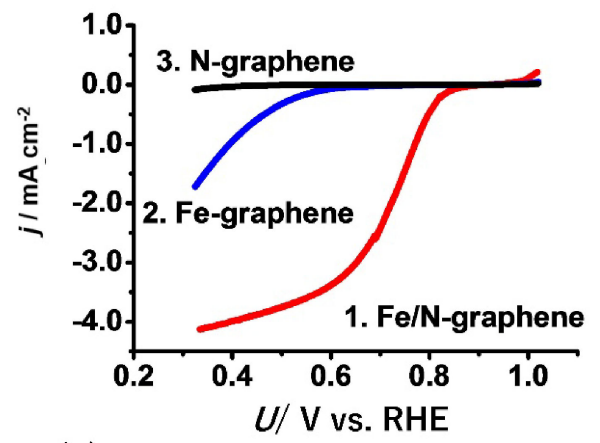

(c)

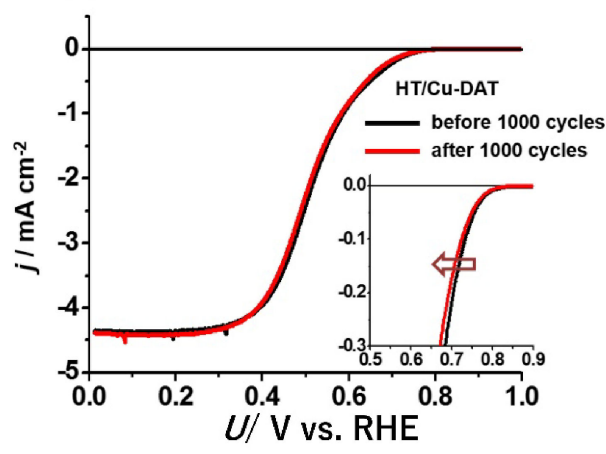

(b)

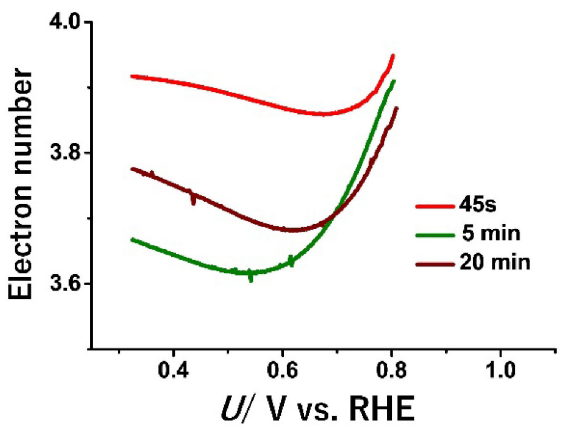

(d)

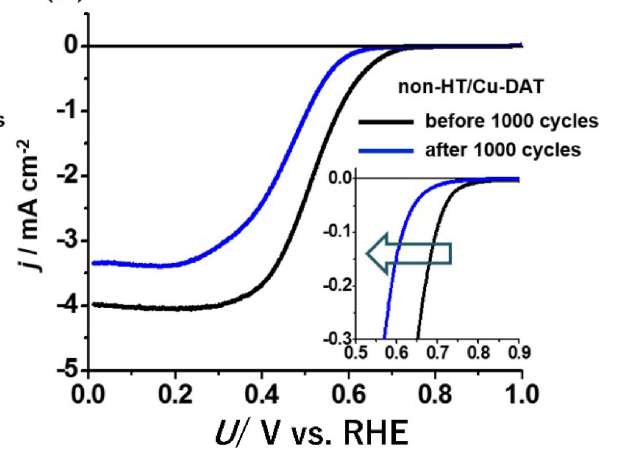

Figure 2. (a) $j$ vs. $U$ curves for $\mathrm{Fe}-\mathrm{N}-\mathrm{Gr}, \mathrm{Fe}-\mathrm{Gr}$, and $\mathrm{N}-\mathrm{Gr}$. Reproduced with permission from Ref. 21 . 2012 The Royal Society of Chemistry. (b) Electron numbers for the Fe-N-Grs after heat treatments for $45 \mathrm{~s}, 5 \mathrm{~min}$, and $20 \mathrm{~min}$. Reproduced with permission from Ref. 22. Copyright 2014 Wiley-VCH Verlag GmbH \& Co. KGaA. (c, d) $j$ vs. $U$ curves for Cu-DAT/graphene (c) with and (d) without the short-duration heat treatment before (black) and after ((c) red, (d) blue) $1000 \mathrm{CV}$ cycles. Electrolytes: (a, b) $0.5 \mathrm{M} \mathrm{H}_{2} \mathrm{SO}_{4}\left(\mathrm{pH}_{0.33)}\right.$ and (c, d) $0.1 \mathrm{M}$ phosphate buffer solution ( $\mathrm{pH} 7.0)$; rotation rate: $1500 \mathrm{rpm}$; scan rate: $10 \mathrm{mV} \mathrm{s}^{-1}$. Reproduced with permission from Elsevier from Ref. 23.

ly became dominant. By contrast, the FEs(CO) of N-Gr and the Nimetal electrode were negligible in all of the examined potential regions, indicating that both $\mathrm{Ni}$ and $\mathrm{N}$ are necessary for high CRR catalytic activity. Importantly, we also confirmed that $\mathrm{Ni} / \mathrm{N}-\mathrm{Gr}$ exhibited excellent stability over a prolonged electrolysis time.

\section{Covalent Organic Frameworks as Supports for Single-metal Sites}

COFs, which are constructed with organic building blocks linked by strong covalent bonds, are promising candidates for catalysts or catalytic supports because of their unique porous structure, robustness, and flexibility of design. ${ }^{31-34}$ Importantly, COFs have abundant heteroatoms such as $\mathrm{N}, \mathrm{O}$, and $\mathrm{S}$ in their pores; thus, they can strongly immobilize various single-metal atoms by forming coordination bonds with these heteroatoms. On the basis of these properties, COFs are considered as ideal supports for SACs. However, the inherent electronic conductivity of COF-based materials is low; thus, COF-based materials exhibit low electrocatalytic activity. Our group has overcome this problem by polymerizing COFs onto conductive carbon nanoparticles (CPs) to form hybrid materials. ${ }^{35}$ The resultant COFs hybridized with CPs can support a wide variety of single-metal atoms via coordination bonds. Interestingly, these metal-doped $\mathrm{COFs}(M-\mathrm{COF})$ exhibit electrocatalytic functions that depend on the metal species (Fig. 4). In this section, we describe our recent work related to SAC-doped COFs.

\subsection{Oxygen-tolerant hydrogen oxidation reaction by single-Pt- doped CTFs}

$\mathrm{Pt}$ is the only practical catalyst for numerous important reactions, including the hydrogen-oxygen fuel cell reaction and the water-gas shift reaction, which are necessary for various environmentally friendly and energy conserving applications. However, because Pt is scarce and expensive, our group has focused on using Pt-SACs to reduce the use of Pt. Moreover, Pt-SACs are expected to exhibit unique reaction selectivity that cannot be achieved with bulk metals or metal nanoclusters. However, Pt-SACs are easily aggregated under electrochemical conditions because of their high surface energy. ${ }^{7}$ We therefore focused on triazine-linked COFs (i.e., covalent triazine frameworks (CTFs)) as a support for Pt-SACs because the CTFs have abundant $\mathrm{N}$ atoms in their pores to immobilize single Pt atoms. Pt-modified CTFs (Pt-CTFs) were synthesized by the polymerization of 2,6-dicyanopyridine in the presence of carbon nanoparticles and the impregnation of Pt into $\mathrm{K}_{2}\left[\mathrm{PtCl}_{4}\right]$ solution was carried out. ${ }^{35,36}$ Figures $5 \mathrm{a}$ and $5 \mathrm{~b}$ show the $\mathrm{Pt} \mathrm{L}_{3}$-edge extended X-ray absorption fine structure (EXAFS) spectrum and a high-angle annular dark-field scanning transmission electron microscopy (HAADF-STEM) image of $0.29 \mathrm{wt} \%$ Pt-CTF. The peak corresponding to Pt-Pt bonds at $2.6 \AA$ is not observed in the EXAFS spectra of the Pt-CTF. In the HAADF-STEM image, bright spots corresponding to $\mathrm{Pt}$ atoms are uniformly dispersed throughout Pt-CTF, whereas almost no Pt nanoparticles are observed. These results indicated that Pt atoms in the Pt-CTF are singly isolated.

We applied Pt-CTF to the hydrogen oxidation reaction, which is a key half-reaction in polymer electrolyte fuel cells (PEFCs). The $j$ vs. $U$ curves obtained with the Pt-CTF in an acidic electrolyte with and without dissolved hydrogen using rotating-disk electrodes (Fig. 6a) clearly indicate that Pt-CTF efficiently catalyzed the hydrogen oxidation reaction (HOR). ${ }^{36}$ The EXAFS spectra and HAADFSTEM image showed that almost all of the Pt atoms in the Pt-CTF were still singly isolated even after the HOR electrolysis, indicating that single Pt atoms served as the catalytic center for the HOR. 
(a)
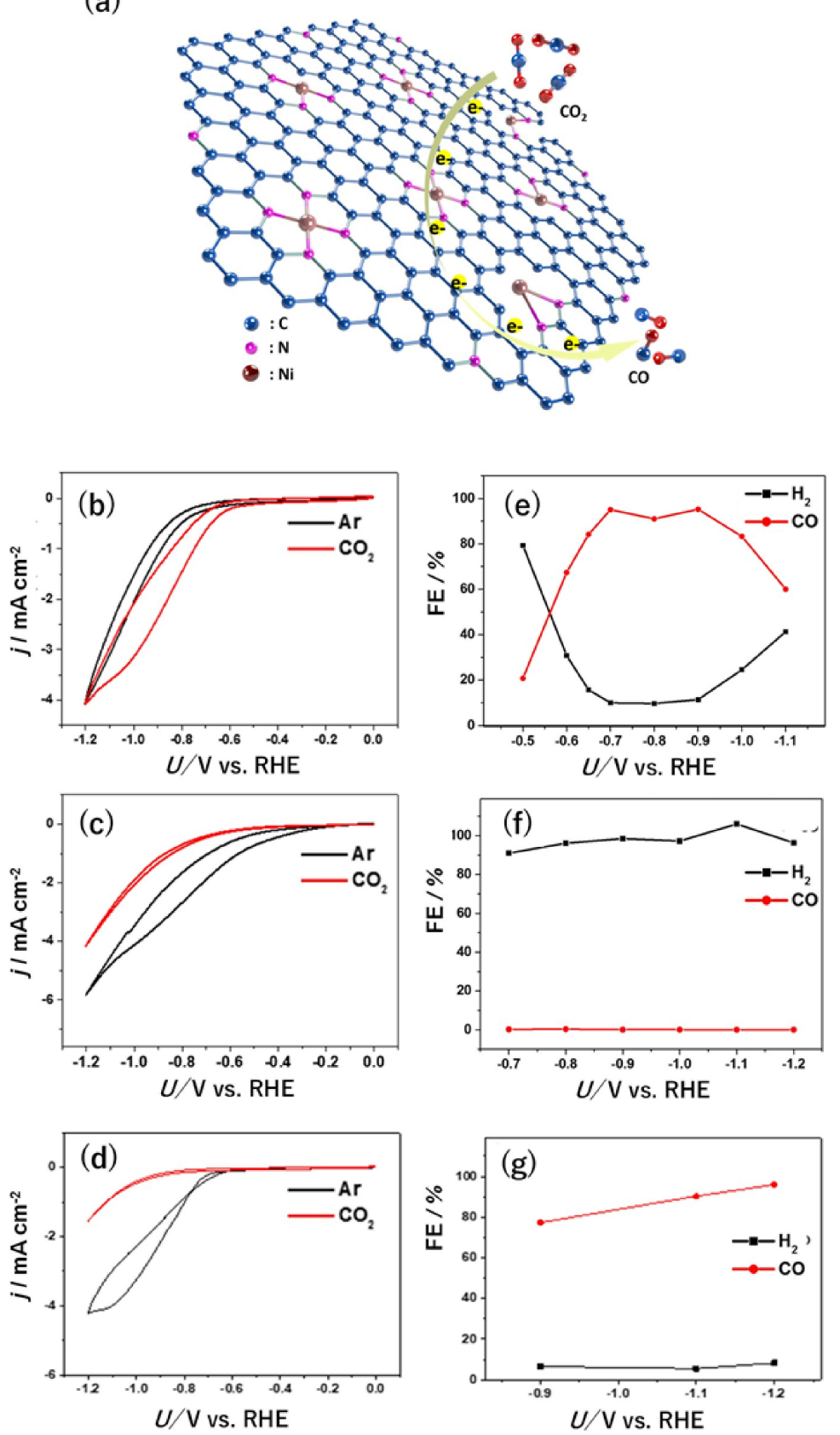

Figure 3. (a) Schematic of $\mathrm{CO}_{2}$ reduction to $\mathrm{CO}$ by Ni/N-Gr. Cyclic voltammograms of (b) Ni/N-Gr, (c) Ni foil, and (d) $\mathrm{N}-\mathrm{Gr}$ in $\mathrm{CO}_{2}-$ saturated $0.1 \mathrm{M} \mathrm{KHCO}_{3}$ and Ar-saturated $0.1 \mathrm{M} \mathrm{KH}_{2} \mathrm{PO}_{4} / \mathrm{K}_{2} \mathrm{HPO}_{4}(\mathrm{pH}=6.8)$ at $10 \mathrm{mV} \mathrm{s}^{-1}$, and FEs for the reduction products generated by (e) Ni/N-Gr, (f) Ni foil, and (g) N-Gr. Reproduced with permission from Ref. 30. Copyright 2016 Wiley-VCH Verlag GmbH \& Co. KGaA.

These results are the first demonstration of the application of PtSACs to HOR electrocatalysis.

We subsequently loaded our Pt-CTF onto a PEFC device as the anode catalyst. A membrane electrode assembly (MEA) with $2.8 \mathrm{wt} \%$ Pt-CTF $\left(0.020 \mathrm{mg}_{-\mathrm{Pt}} \mathrm{cm}^{-2}\right)$ or $20 \mathrm{wt} \% \quad \mathrm{Pt} / \mathrm{C} \quad(0.10$ $\mathrm{mg}_{-\mathrm{Pt}} \mathrm{cm}^{-2}$ ) as the anode and $47 \mathrm{wt} \% \mathrm{Pt} / \mathrm{C}$ as the cathode catalyst was fabricated. ${ }^{36}$ The obtained $j-U$ curves (solid lines) and $j$-power density curves are shown in Fig. 6b. Notably, although the amount of $\mathrm{Pt}$ in the Pt-CTF anode was five times lower than that in the $\mathrm{Pt} / \mathrm{C}$ anode, the power output with the Pt-CTF anode was almost equal to that with the $\mathrm{Pt} / \mathrm{C}$ anode because the number of electrochemically active $\mathrm{Pt}$ atoms on the Pt-CTF was much larger than that on the $\mathrm{Pt} / \mathrm{C}$ since the Pt was in single-atom form.

The Pt-SAC also exhibited an oxygen tolerance during the HOR. Figure $6 \mathrm{c}$ shows the change in the HOR current at $0.6 \mathrm{~V}$ vs. RHE for Pt-CTF and conventional Pt/C catalysts. These two catalysts showed comparable HOR currents under pure $\mathrm{H}_{2}$ gas. However, for the $\mathrm{Pt} / \mathrm{C}$ catalysts, the polarity of the current shifted from anodic to cathodic upon the $\mathrm{O}_{2}$ addition because the large cathodic ORR current overlapped with the HOR; by contrast, Pt-CTF showed little change in the HOR current upon the introduction of $\mathrm{O}_{2} \cdot{ }^{36}$ These results clearly show that Pt-CTF exhibited high oxygen tolerance.

The ORR pathway through the end-on adsorption of $\mathrm{O}_{2}$ molecules on a $\mathrm{Pt}$ atom is known to require a higher activation energy than the pathway involving bridge-type adsorption. ${ }^{37}$ Because only the reactions via the end-on pathway can proceed on single Pt atoms, Pt-CTF reasonably exhibited lower ORR activity than $\mathrm{Pt} / \mathrm{C}$. Air contaminates fuel chambers, and the ORR proceeds on conventional $\mathrm{Pt} / \mathrm{C}$ catalysts during $\mathrm{PEFC}$ startup, ${ }^{38}$ leading to degradation of the carbon particles onto the oxygen chamber (i.e., at 


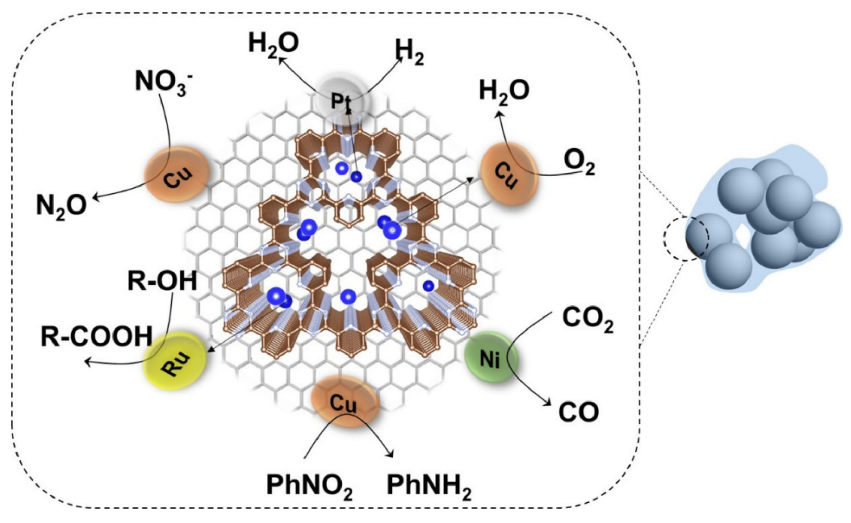

Figure 4. Various electrocatalytic functions of metal-doped CTF/ carbon nanoparticle hybrids. (In the left image, brown and white balls are $\mathrm{C}$ and $\mathrm{N}$ atoms of CTF framework, respectively. A pale honeycomb structure represents the $s p 2$ structure of carbon nanoparticles.)
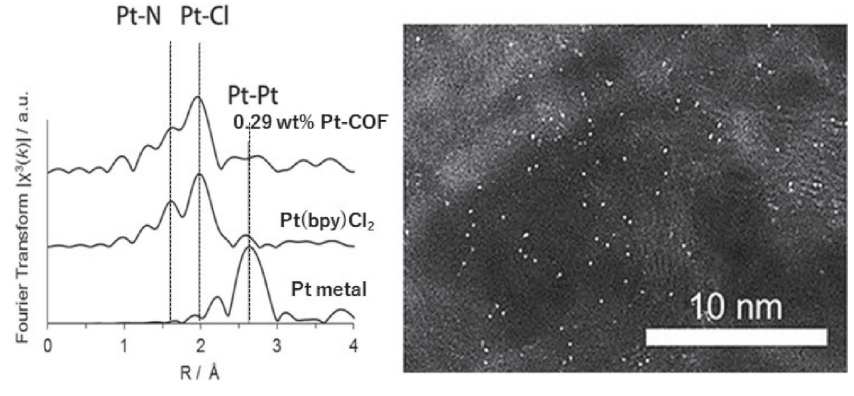

Figure 5. (a) Fourier transformations of $k^{3}$-weighted $\mathrm{Pt} \mathrm{L}_{3}$-edge EXAFS oscillations and (b) a HAADF-STEM image of $0.29 \mathrm{wt} \%$ Pt-CTF. Reproduced with permission from Ref. 36. Copyright 2016 Wiley-VCH Verlag GmbH \& Co. KGaA.

the cathode). Thus, the $\mathrm{O}_{2}$ tolerance is a quite important for the anode of a PEFC.

In addition to an $\mathrm{O}_{2}$-tolerant HOR, the Pt-CTFs also show various unique electrocatalytic selectivities. ${ }^{35,39-44}$ For example, although the ORR activity of Pt-CTF is not as promising as its HOR activity, it exhibits excellent methanol tolerance during the ORR, which is an attractive property for anode catalysts used in direct methanol fuel cells. ${ }^{35} \mathrm{Pt}-\mathrm{CTF}$ was also inactive toward the nitrate reduction reaction, which is facilitated by bulk Pt metal. The unique selectivity of Pt-CTF, which was attributed to the atomic dispersion of Pt atoms, enables the use of low-purity substrates for electrolysis.

\subsection{Oxygen reduction reaction by Cu-doped CTFs}

In Cu-containing enzymes, such as bilirubin oxidase and laccase, $\mathrm{Cu}$ serves as the active center for the ORR. In particular, multicopper oxidases are known to catalyze the electrochemical ORR in neutral solutions with almost no overpotential, indicating that $\mathrm{Cu}$ could potentially exhibit catalytic activity superior to that of Pt. ${ }^{45,46}$ However, artificial $\mathrm{Cu}$ macrocyclic compounds (Cu-N4) such as $\mathrm{Cu}$-porphyrin and $\mathrm{Cu}$-phthalocyanine exhibit almost no ORR activity. Thorseth et al. reported that the binding strength between $\mathrm{Cu}$ sites in $\mathrm{Cu}-\mathrm{N} 4$ and $\mathrm{O}_{2}$ molecules is too weak to activate $\mathrm{O}-\mathrm{O}$ bonds, resulting in poor ORR activity. ${ }^{47}$ One of the critical factors affecting the binding strength between metal centers and intermediates or substrates is the coordination structure, especially the coordination number $(\mathrm{CN})$. Our group and others have demonstrated using first-principles calculations that the metal centers with a lower $\mathrm{CN}$ generally adsorb various reaction intermediates more strongly than those with a higher $\mathrm{CN} .{ }^{48-50}$ Therefore, low- $\mathrm{CN} \mathrm{Cu}$ sites might be active toward the ORR. Although coordinatively unsaturated metal sites are generally unstable, the rigid porous framework of CTF is expected to stabilize open-coordination single-metal sites. Therefore, we prepared a Cu-doped CTF (Fig. 7a) and investigated its electrocatalytic ORR activity. ${ }^{51,52}$

Figure $7 \mathrm{~b}$ shows the EXAFS spectra of $\mathrm{Cu}-\mathrm{CTF}(0.6$ at $\% \mathrm{Cu})$. A peak at $0.16 \mathrm{~nm}$ corresponding to the $\mathrm{Cu}-\mathrm{N}$ bond was observed, whereas peaks corresponding to $\mathrm{Cu}-\mathrm{Cu}(0.22 \mathrm{~nm})$ and $\mathrm{Cu}-\mathrm{O}-\mathrm{Cu}$ bonds $(0.27 \mathrm{~nm})$ were not detected, indicating $\mathrm{Cu}$ atoms in $\mathrm{Cu}-\mathrm{CTF}$ were single isolated atoms. Figures $7 \mathrm{c}$ and $7 \mathrm{~d}$ show $j$ vs. $U$ curves for $\mathrm{Cu}-\mathrm{CTF}$ and $\mathrm{CTF}$ in neutral solutions and without and with $\mathrm{O}_{2}$, respectively. Although no redox peaks were observed for the CTF in Ar-saturated phosphate buffer solution, a single pair of redox peaks with a midpoint potential of $0.57 \mathrm{~V}$ vs. RHE was detected in the curves for $\mathrm{Cu}-\mathrm{CTF}$, which was ascribed to the $\mathrm{Cu}(\mathrm{II}) / \mathrm{Cu}(\mathrm{I})$ redox couple. The ORR onset potential for $\mathrm{Cu}-\mathrm{CTF}$ was $0.81 \mathrm{~V}$ vs. RHE, as shown in Fig. $7 \mathrm{~d}$, and was $0.13 \mathrm{~V}$ higher than that for CTF, indicating that the $\mathrm{Cu}$ in $\mathrm{Cu}-\mathrm{CTF}$ can exhibit catalytic activity toward the ORR. ${ }^{51,52}$ Notably, the ORR onset potential is consistent with the potential at which $\mathrm{Cu}(\mathrm{II})$ was converted to $\mathrm{Cu}(\mathrm{I})$, suggesting that the ORR was mediated by the $\mathrm{Cu}(\mathrm{I})$ species. The ORR onset potential $(0.81 \mathrm{~V}$ vs. RHE) is one of the highest values reported for a synthetic $\mathrm{Cu}$-based ORR catalyst. On the basis of the curve fitting of the EXAFS spectrum (Fig. 7a), the $\mathrm{CN}$ of the $\mathrm{Cu}$ site in $\mathrm{Cu}-\mathrm{CTF}$ was calculated to be 3.4, which is lower than that in $\mathrm{Cu}$ (a)

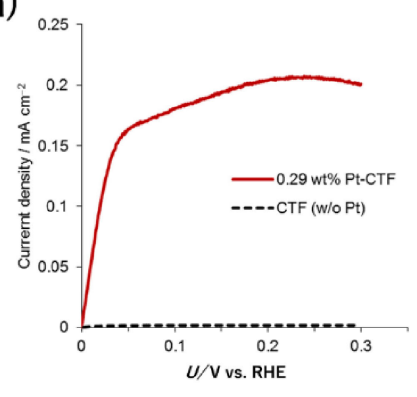

(b)

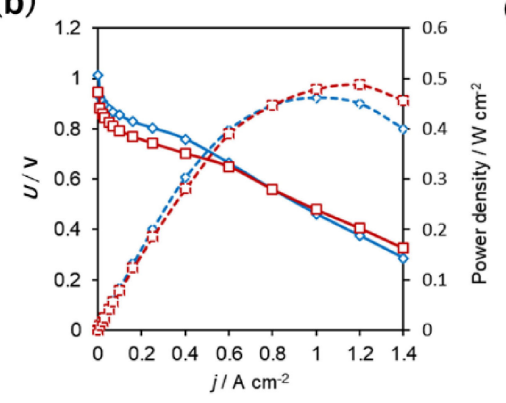

(c)

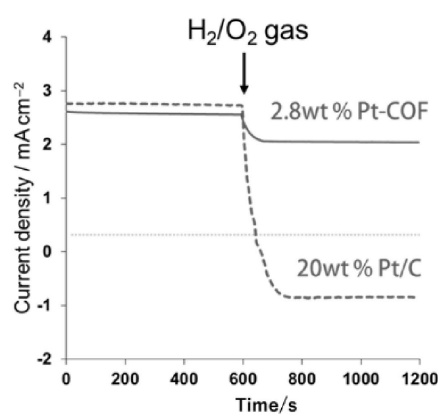

Figure 6. (a) $j$ vs. $U$ curves for $0.29 \mathrm{wt} \%$ Pt-CTF and $\mathrm{CTF}$ in $\mathrm{H}_{2}$-saturated $0.1 \mathrm{M} \mathrm{HClO}_{4}$. Scan rate: $5 \mathrm{mV} \mathrm{s}^{-1}$; rotational rate: $2500 \mathrm{rpm}$. (b) Fuel cell output of membrane electrode assemblies. The anodes prepared with (red) $2.8 \mathrm{wt} \% \mathrm{Pt}-\mathrm{CTF}$ and (blue) $20 \mathrm{wt} \% \mathrm{Pt} / \mathrm{C}$ were loaded with 0.020 and $0.10 \mathrm{mg}_{-\mathrm{Pt}} \mathrm{cm}^{-2}$, respectively. (c) Chronoamperometric curves (solid line) $2.8 \mathrm{wt} \% \mathrm{Pt}-\mathrm{CTF}$ and (dashed line) $20 \mathrm{wt} \% \mathrm{Pt} / \mathrm{C}$ in $0.1 \mathrm{M} \mathrm{HClO}_{4}$ at $+0.6 \mathrm{~V}$ vs. RHE. The input gas was changed at $600 \mathrm{~s}$ (indicated by the arrow) from pure $\mathrm{H}_{2}$ to a mixed gas consisting of $\mathrm{H}_{2}$ and $\mathrm{O}_{2}\left(\mathrm{H}_{2}: \mathrm{O}_{2}=1: 1\right)$. Reproduced with permission from Ref. 36. Copyright 2016 Wiley-VCH Verlag GmbH \& Co. KGaA. 
(a)

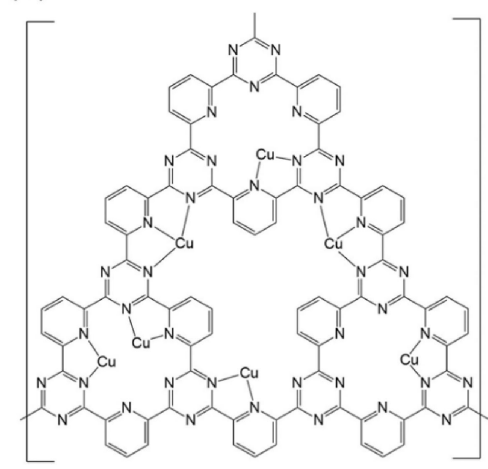

(c)

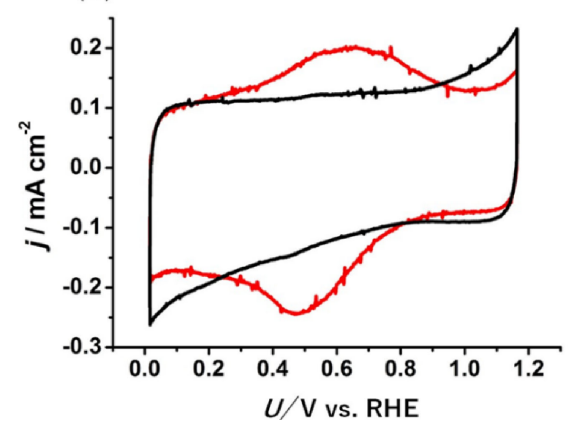

(b)

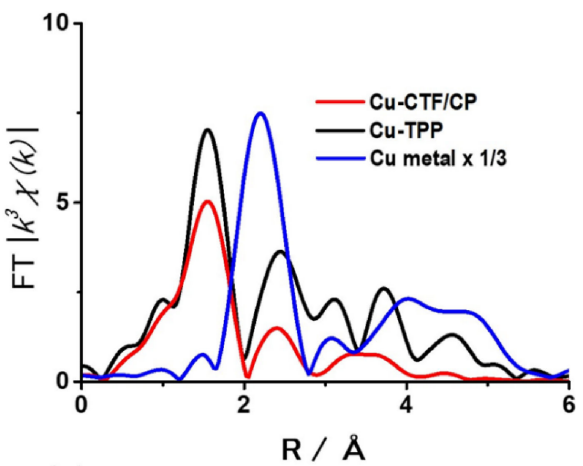

(d)

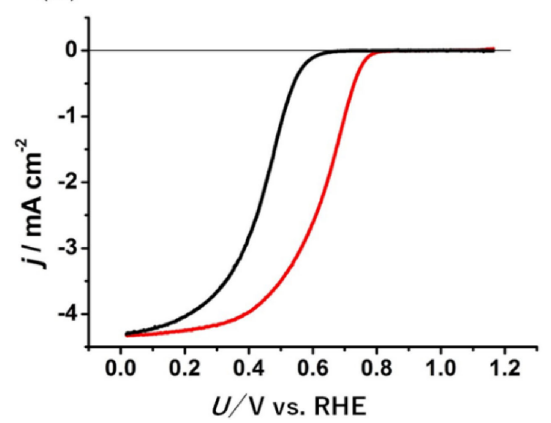

Figure 7. (a) Schematic of the Cu-CTF. (b) Fourier transformations of $k^{3}$-weighted $\mathrm{Cu}$ K-edge EXAFS oscillations for $\mathrm{Cu}-\mathrm{CTF}$ (red), $\mathrm{Cu}$ TPP (black), and $\mathrm{Cu}$ metal (blue). (c, d) $j$ vs. $U$ curves under (c) $\mathrm{Ar}$ and (d) $\mathrm{O}_{2}$ for Cu-CTF (red) and CTF (black) in phosphate buffer solution (pH 7). Reproduced with permission from Ref. 51. Copyright 2015 Wiley-VCH Verlag GmbH \& Co. KGaA.

macrocycles. ${ }^{40,48,53-55}$ Thus, as expected, the unsaturated coordination structure of $\mathrm{Cu}$ sites in $\mathrm{Cu}-\mathrm{CTF}$ might strongly bind $\mathrm{O}_{2}$ molecules, resulting in high ORR activity. The other important aspect of $\mathrm{Cu}-\mathrm{CTF}$ is its high stability compared with that of $\mathrm{Cu}-$ based organometallic catalysts due to the rigid cross-linked covalent bonds in CTFs.

\section{3 $\mathrm{CO}_{2}$ reduction reaction by $\mathrm{Ni}$-doped $\mathrm{CTFs}$}

We extended the application of $M$-CTFs to electrocatalysis of the CRR to CO. In general, Co- or Fe-based macrocycles are known to exhibit effective activity toward $\mathrm{CO}_{2}$ reduction to $\mathrm{CO}^{56,57}$ In contrast, $\mathrm{Ni}$ - or $\mathrm{Cu}$-based macrocycles show inferior $\mathrm{CO}$ generation activity because of excessively weak adsorption with $\mathrm{COOH}$, which is the key intermediate for $\mathrm{CO}^{56}$ Given that the adsorption energy of $\mathrm{O}_{2}$ on $\mathrm{Cu}-\mathrm{CTF}$ is larger than that on $\mathrm{Cu}$-porphyrin, as previously described, we expected the unsaturated metal centers in CTFs to strongly interact with $\mathrm{COOH}$. That is, CTFs may improve the performance of metal species which had been thought to exhibit no CRR catalytic activity. We therefore synthesized CTFs doped with $3 d$ metal atoms $(\mathrm{Co}, \mathrm{Ni}$, and $\mathrm{Cu})$ as electrocatalysts for CRRs.

EXAFS analysis confirmed that the obtained Ni-CTFs $(\mathrm{CN}=$ 3.4) and Co-CTF $(\mathrm{CN}=3.2)$ have an unsaturated coordination structure in a similar manner with $\mathrm{Cu}-\mathrm{CTF}$ (see section 3.2) ${ }^{58}$ The potential dependences of the FEs for CO formation for $M$-CTFs and $M$-TPPs in neutral solutions are shown in Figs. $8 \mathrm{a}$ and $8 \mathrm{~b}$, respectively. Only Co-TPP exhibited CRR activity in $M$-TPPs; by contrast, not only Co-CTF but Ni-CTF effectively reduced $\mathrm{CO}_{2}$ to $\mathrm{CO}$. Ni-CTF exhibited the highest activity toward $\mathrm{CO}$ formation, with an FE exceeding $90 \%$ at -0.8 to -0.9 V vs. RHE. ${ }^{58,59}$ Notably, $\mathrm{H}_{2}$ was the other major product in all cases.

We subsequently studied the origin of the differences in the activities of the $M$-CTF and $M$-TPP using density functional theory (DFT) calculations. Figures $8 \mathrm{c}$ and $8 \mathrm{~d}$ show free-energy diagrams for the conversion of $\mathrm{CO}_{2}$ to $\mathrm{CO}$ on $M$-TPP and $M$-CTF. The overall reaction pathway on the Co-TPP is exergonic, whereas the step to form the adsorbed $\mathrm{COOH}\left(\mathrm{COOH}^{*}\right)$ is an endothermic reaction for the $\mathrm{Cu}$ - or Ni-TPPs. In contrast to $M$-TPPs, not only Co-CTF but also Ni-CTF exhibited exergonic $\mathrm{COOH}^{*}$ formation (Fig. 8d), which corresponds to their electrocatalytic activities (Fig. 8b). The low energy barrier to the formation of $\mathrm{COOH}^{*}$ for $\mathrm{Ni}-\mathrm{CTF}$ resulted from the unsaturated coordination structures of metal centers in CTFs. ${ }^{58}$

\section{Conclusion}

This comprehensive article presented an overview of our recent studies on robust heterogeneous electrocatalysts comprising singleatom sites with designed coordination structures. Molecular structures of metal precursors were retained in the resultant catalysts by the short-duration heat treatment of mixtures of graphene oxides and metal complexes. The obtained $M-\mathrm{N}-\mathrm{Grs}$ exhibit both high catalytic activity and high durability for the ORR and CRR. In the case of SAC-COFs, because the electronic and geometric structures of the COFs can be modified at will due to the choice of the building blocks, coordination structures of SACs, such as $\mathrm{CN}$ and neighboring atoms, are easily tuned. Therefore, we anticipate that single-atom active sites with a designed coordination structure will be a new platform for heterogeneous electrocatalysts for various useful reactions. As our SACs feature both high stability and high design flexibility, they are expected to be loaded into various useful systems such as artificial photosynthesis systems and chemical batteries.

\section{Acknowledgment}

The author would like to express sincere gratitude to Professor Shuji Nakanishi (Osaka University) and Professor Kazuhito Hashimoto (National Institute for Materials Science) for their 
(a)

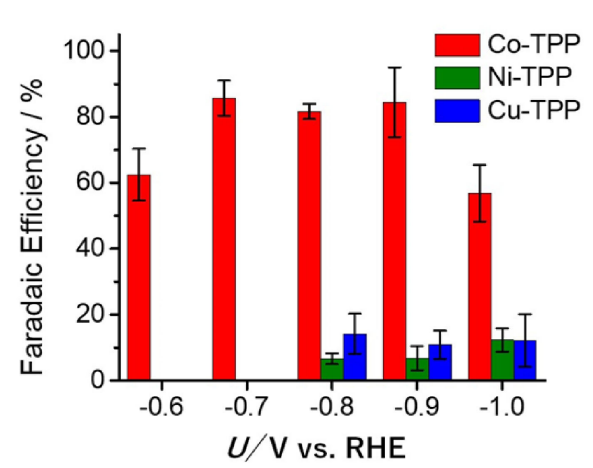

(c)

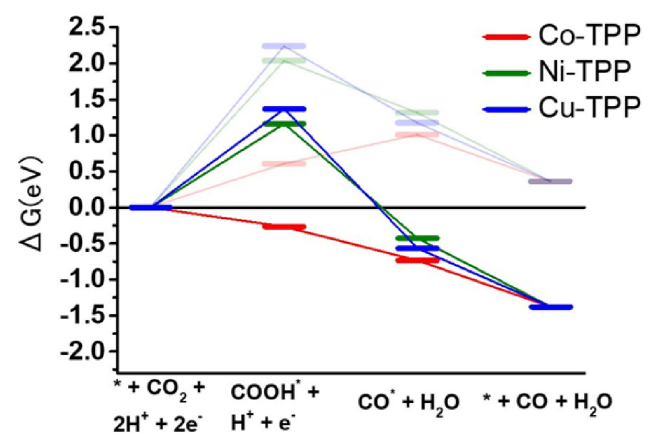

(b)

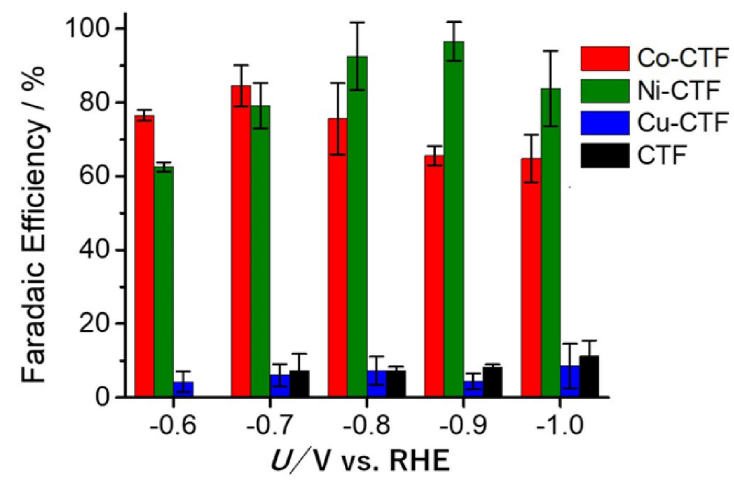

(d)

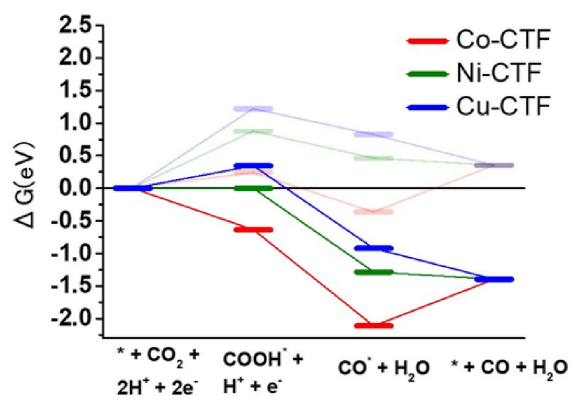

Figure 8. (a, b) The faradaic efficiencies for $\mathrm{CO}$ production on (a) $M$-TPPs and (b) $M$-CTFs in a $\mathrm{KHCO}_{3}$ electrolyte (saturated with $\mathrm{CO}_{2}$ ) at $\mathrm{pH}$ 6.8. (c, d) Free-energy diagrams of the $\mathrm{CO}$ generation for (c) $M$-TPPs and (d) $M$-CTFs at (pale lines) $0 \mathrm{~V}$ and (dark lines) $-0.87 \mathrm{~V}$ vs. computational hydrogen electrode. Reproduced from Ref. 58 under the CC BY 3.0 license.

continuous support and guidance. The author also would like to thank all collaborators. This research was supported by a JSPS KAKENHI Program (20H02568 and 17H04798), CREST (grant JPMJCR18R3), and PRESTO Program (grant JPMJPR1415) of the Japan Science and Technology Agency (JST). The synchrotron radiation experiments were performed at the BL01B1 beam line of SPring-8 with the approval of the Japan Synchrotron Radiation Research Institute (JASRI) (Proposal Nos. 2015B1174, 2016A1464, 2017A1790, 2018A1349, 2019A1394 and 2019B1159).

\section{References}

1. Z. Chang, J. Xu, and X. Zhang, Adv. Energy Mater, 7, 1700875 (2017).

2. A. Zahoor, Z. K. Ghouri, S. Hashmi, F. Raza, S. Ishtiaque, S. Nadeem, I. Ullah, and K. S. Nahm, ACS Sustainable Chem. Eng., 7, 14288 (2019).

3. D. Kim, K. K. Sakimoto, D. Hong, and P. Yang, Angew. Chem., Int. Ed., 54, 3259 (2015)

4. J. Barber and P. D. Tran, J. R. Soc., Interface, 10, 20120984 (2013).

5. V. Rosca, M. Duca, M. T. de Groot, and M. T. M. Koper, Chem. Rev., 109, 2209 (2009)

6. M. R. Gandhi, S. Vasudevan, A. Shibayama, and M. Yamada, ChemistrySelect, 1, 4358 (2016).

7. X. F. Yang, A. Wang, B. Qiao, J. Li, J. Liu, and T. Zhang, Acc. Chem. Res., 46, 1740 (2013).

8. Y. Zhu, W. Peng, Y. Li, G. Zhang, F. Zhang, and X. Fan, Small Methods, 3, 1800438 (2019)

9. H. Fei, J. Dong, D. Chen, T. Hu, X. Duan, I. Shakir, Y. Huang, and X. Duan, Chem. Soc. Rev., 48, 5207 (2019).

10. H. Li, H. Zhu, Z. Zhuang, S. Lu, F. Duan, and M. Du, Sustainable Energy Fuels, 4, 996 (2020).

11. K. Ding, A. Gulec, A. M. Johnson, N. M. Schweitzer, G. D. Stucky, L. D. Marks, and P. C. Stair, Science, 350, 189 (2015).

12. J. Kim, H.-E. Kim, and H. Lee, ChemSusChem, 11, 104 (2018).

13. H. Jahnke, M. Schonborn, and G. Zimmermann, Top. Curr. Chem., 61, 133 (1976).

14. V. S. Bagotzky, M. R. Tarasevich, K. A. Radyushkina, O. A. Levina, and S. I. Andrusyova, J. Power Sources, 2, 233 (1978).
15. M. Lefèvre, E. Proietti, F. Jaouen, and J.-P. Dodelet, Science, 324, 71 (2009).

16. G. Wu, K. L. More, C. M. Johnston, and P. Zelenay, Science, 332, 443 (2011).

17. H. Niwa, K. Horiba, Y. Harada, M. Oshima, T. Ikeda, K. Terakura, J.-i. Ozaki, and S. Miyata, J. Power Sources, 187, 93 (2009).

18. Y. Zhao, K. Kamiya, K. Hashimoto, and S. Nakanishi, J. Phys. Chem. C, 119, 2583 (2015).

19. Y. Zhao, K. Kamiya, K. Hashimoto, and S. Nakanishi, J. Mater. Chem. A, 4, 3858 (2016).

20. S. Fa, M. Yamamoto, H. Nishihara, R. Sakamoto, K. Kamiya, Y. Nishina, and T. Ogoshi, Chem. Sci., 11, 5866 (2020).

21. K. Kamiya, K. Hashimoto, and S. Nakanishi, Chem. Commun., 48, 10213 (2012).

22. K. Kamiya, H. Koshikawa, H. Kiuchi, Y. Harada, M. Oshima, K. Hashimoto, and S. Nakanishi, ChemElectroChem, 1, 877 (2014).

23. H. Koshikawa, S. Nakanishi, K. Hashimoto, and K. Kamiya, Electrochim. Acta, 180, 173 (2015).

24. J. D. Froehlich and C. P. Kubiak, J. Am. Chem. Soc., 137, 3565 (2015).

25. C. A. Kelly, Q. G. Mulazzani, M. Venturi, E. L. Blinn, and M. A. J. Rodgers, J. Am. Chem. Soc., 117, 4911 (1995).

26. A. S. Varela, N. Ranjbar Sahraie, J. Steinberg, W. Ju, H.-S. Oh, and P. Strasser, Angew. Chem., Int. Ed., 54, 10758 (2015).

27. W. Ju, A. Bagger, G.-P. Hao, A. S. Varela, I. Sinev, V. Bon, B. Roldan Cuenya, S. Kaskel, J. Rossmeisl, and P. Strasser, Nat. Commun., 8, 944 (2017).

28. H. Nishihara, T. Hirota, K Matsuura, M. Ohwada, N. Hoshino, T Akutagawa, T Higuchi, H. Jinnai, Y. Koseki, H. Kasai, Y. Matsuo, J. Maruyama, Y. Hayasaka, H. Konaka, Y. Yamada, S. Yamaguchi, K. Kamiya, T. Kamimura, H. Nobukuni, and F. Tani, Nat. Commun., 8, 109 (2017).

29. H. Nishihara, K. Matsuura, M. Ohwada, M. Yamamoto, Y. Matsuo, J. Maruyama, Y. Hayasaka, S. Yamaguchi, K. Kamiya, H. Konaka, M. Inoue, and F. Tani, Chem. Lett., 49, 619 (2020).

30. P. Su, K. Iwase, S. Nakanishi, K. Hashimoto, and K. Kamiya, Small, 12, 6083 (2016).

31. A. P. Cote, A. I. Benin, N. W. Ockwig, M. O'Keeffe, A. J. Matzger, and O. M. Yaghi, Science, 310, 1166 (2005).

32. P. J. Waller, F. Gandara, and O. M. Yaghi, Acc. Chem. Res., 48, 3053 (2015)

33. S. Y. Ding and W. Wang, Chem. Soc. Rev., 42, 548 (2013).

34. X. Feng, X. S. Ding, and D. L. Jiang, Chem. Soc. Rev, 41, 6010 (2012).

35. K. Kamiya, R. Kamai, K. Hashimoto, and S. Nakanishi, Nat. Commun., 5, 5040 (2014).

36. R. Kamai, K. Kamiya, K. Hashimoto, and S. Nakanishi, Angew. Chem., Int. Ed., 
55, 13184 (2016).

37. S. Yang, J. Kim, Y. J. Tak, A. Soon, and H. Lee, Angew. Chem., Int. Ed., 55, 2058 (2016).

38. R. B. Kaspar, J. A. Wittkopf, M. D. Woodroof, M. J. Armstrong, and Y. Yan, J. Electrochem. Soc., 163, F377 (2016)

39. R. Kamai, S. Nakanishi, K. Hashimoto, and K. Kamiya, J. Electroanal. Chem., 800, 54 (2017).

40. K. Kamiya, T. Tatebe, S. Yamamura, K. Iwase, T. Harada, and S. Nakanishi, ACS Catal., 8, 2693 (2018).

41. S. Yamaguchi, K. Kamiya, K. Hashimoto, and S. Nakanishi, Chem. Commun., 53, 10437 (2017).

42. K. Kamiya, Impact, 2018, 57 (2018)

43. H. Tabata, S. Kato, S. Yamaguchi, T. Harada, K. Iwase, K. Kamiya, and S. Nakanishi, Chem. Lett., 49, 513 (2020).

44. S. Kato, K. Iwase, T. Harada, S. Nakanishi, and K. Kamiya, ACS Appl. Mater. Interfaces, 12, 29376 (2020).

45. N. Mano, V. Soukharev, and A. Heller, J. Phys. Chem. B, 110, 11180 (2006).

46. R. Nakamura, K. Kamiya, and K. Hashimoto, Chem. Phys. Lett., 498, 307 (2010).

47. M. A. Thorseth, C. E. Tornow, E. C. M. Tse, and A. A. Gewirth, Coord. Chem. Rev., 257, 130 (2013).

48. K. Iwase, S. Nakanishi, M. Miyayama, and K. Kamiya, ACS Appl. Energy Mater.
3, 1644 (2020).

49. F. Calle-Vallejo, D. Loffreda, M. T. M. Koper, and P. Sautet, Nat. Chem., 7, 403 (2015).

50. Z. Zhao, Z. Chen, X. Zhang, and G. Lu, J. Phys. Chem. C, 120, 28125 (2016).

51. K. Iwase, T. Yoshioka, S. Nakanishi, K. Hashimoto, and K. Kamiya, Angew. Chem., Int. Ed., 54, 11068 (2015).

52. K. Iwase, K. Kamiya, M. Miyayama, K. Hashimoto, and S. Nakanishi, ChemElectroChem, 5, 805 (2018).

53. T. Yoshioka, K. Iwase, S. Nakanishi, K. Hashimoto, and K. Kamiya, J. Phys. Chem. C, 120, 15729 (2016).

54. K. Iwase, N. Fujinami, K. Hashimoto, K. Kamiya, and S. Nakanishi, Chem. Lett., 47, 304 (2018).

55. K. Kamiya, R. Sugimoto, T. Tatebe, T. Harada, and S. Nakanishi, ChemSusChem, 13, 3462 (2020).

56. N. Sonoyama, M. Kirii, and T. Sakata, Electrochem. Commun., 1, 213 (1999).

57. V. Tripkovic, M. Vanin, M. Karamad, M. E. Björketun, K. W. Jacobsen, K. S. Thygesen, and J. Rossmeisl, J. Phys. Chem. C, 117, 9187 (2013).

58. P. Su, K. Iwase, T. Harada, K. Kamiya, and S. Nakanishi, Chem. Sci., 9, 3941 (2018).

59. Y. Wu, K. Kamiya, T. Hashimoto, R. Sugimoto, T. Harada, K. Fujii, and S. Nakanishi, Electrochemistry, (2020). 